\title{
Produtividade, renda e bromatologia dos taros Chinês e Macaquinho em resposta a formas de adição ao solo da cama-de-frango
}

\section{Yield, income and bromatology of 'Chinês' and 'Macaquinho' taro in response to forms of adding chicken manure to the soil}

\author{
Néstor Antonio Heredia Zárate ${ }^{1 *}$; Marcela Machado de Resende ${ }^{2}$; \\ Maria do Carmo Vieira'; Elissandra Pacito Torales ${ }^{3}$; \\ Fabiane Cargnin Faccin ${ }^{4}$; Natália Andressa Salles ${ }^{4}$
}

\begin{abstract}
Resumo
A produtividade do taro é muito variável pelo desconhecimento das características genotípicas e pelas diferenças nas práticas de plantio, principalmente sobre o uso de resíduos orgânicos a serem utilizados como cobertura morta ou incorporados ao solo. O objetivo deste trabalho foi analisar a produtividade, a renda bruta e a composição bromatológica dos taros Chinês e Macaquinho, cultivados com diferentes formas de adição ao solo de cama-de-frango semi-decomposta (solo sem cama-de-frango; com camade-frango em cobertura; com cama-de-frango incorporada e com cama-de-frango em cobertura + incorporada). Os tratamentos foram arranjados em esquema fatorial $2 \times 4$, no delineamento experimental de blocos casualizados, com cinco repetições. Visando conhecer melhor o comportamento dos clones optou-se por efetuar colheitas aos 183 e aos 211 dias após o plantio. Não houve diferença para maioria das características em função da adição da cama-de-frango. O clone Macaquinho foi superior ao Chinês para produção de rizomas-filho comerciais sendo esse ponto favorável para uma maior renda bruta. As plantas do taro 'Macaquinho' foram precoces e mais produtivas que as do 'Chinês'. Para obter maior renda bruta deve-se cultivar o taro Macaquinho com adição ao solo de cama-de-frango em cobertura (5 t $\left.\mathrm{ha}^{-1}\right)+$ incorporada $\left(5 \mathrm{t} \mathrm{ha}^{-1}\right)$ e realizar a colheita aos 183 dias após o plantio. Pela análise bromatológica, os rizomas-mãe e rizomas-filho do taro 'Chinês' apresentaram melhores características nutritivas do que os do 'Macaquinho', quando cultivados sem cama-de-frango.
\end{abstract}

Palavras-chave: Colocasia esculenta, resíduo orgânico, rentabilidade, composição nutritiva

\begin{abstract}
Yield of Taro is very variable by the unknowing of its genotype characteristics and by differences of planting practices, mainly about the use of organic residues as covering or incorporated to the soil. The aim of this work was to analyze the productivity, gross income and bromatological composition of 'Chinês' and 'Macaquinho' taro, cultivated with different forms of adding semi-decomposed chicken manure to the soil (soil without chicken manure; with chicken manure as covering; with chicken manure incorporated to the soil and with chicken manure as covering + incorporated to the soil). Treatments
\end{abstract}

\footnotetext{
1 Profs. Drs. Bolsista de Produtividade em Pesquisa do CNPq. Universidade Federal da Grande Dourados, Faculdade de Ciências Agrárias, UFGD, Dourados, MS. E-mail: nahz@terra.com.br; vieiracm@terra.com.br

2 M.e em Agronomia, UFGD, Dourados, MS. E-mail: marceladeresende@hotmail.com

3 Discente de Pós-graduação do Curso de Doutorado em Agronomia, UFGD, Dourados, MS. E-mail: ninapacito@hotmail.com

4 Discentes de Graduação em Agronomia, UFGD, Dourados, MS. Bolsistas de Iniciação Científica CNPq/UFGD. E-mail: fabiane_ faccin@hotmail.com; natalia.asalles@gmail.com

* Autor para correspondência
} 
were arranged in a $2 \times 4$ factorial scheme in a randomized complete block design with five replications. Two harvests were performed at 183 and 211 days after transplanting. There was no difference for most of the characteristics evaluated under addiction of chicken manure. Yields of commercial cormels from Macaquinho were higher than Chinês, which can be seen as positive feature for higher gross income. Plants of 'Macaquinho' taro were precocious and more productive than 'Chinês' taro. To obtain higher gross income, 'Macaquinho' taro must be cultivated with adding chicken manure to the soil as covering $\left(5 \mathrm{t} \mathrm{ha}^{-1}\right)+$ incorporated to the soil $\left(5 \mathrm{t} \mathrm{ha}^{-1}\right)$ and harvested 183 days after planting. Bromatological analysis showed that corms and cormels of 'Chinês' taro were more nutritious than 'Macaquinho' taro when grown without chicken manure.

Key words: Colocasia esculenta, organic residue, profitability, nutritive composition

\section{Introdução}

O taro é uma hortaliça com considerável valor nutricional, apresentando elevado teor de amido, o que permite tanto seu consumo in natura quanto sua utilização como matéria-prima para a agroindústria (VILPOUX, 2001). Por suas características nutricionais, o taro apresenta possibilidades de uso humano sob diferentes formas de preparo, podendo substituir, total ou parcialmente, a batatinha, a mandioca, o milho, o trigo e outras espécies amídicas. Também, pode ser utilizado na alimentação animal, especialmente para frangos de corte (HEREDIA ZÁRATE et al., 2005). O valor dos alimentos está relacionado com sua composição química e são variáveis em função da idade de colheita, tratos culturais, cuidados de conservação entre outros. A análise química-bromatológica fornece essas informações assim como examina a condição de pureza dos alimentos, sejam elas de natureza orgânica ou inorgânica (SILVA; QUEIROZ, 2002).

A cultura de taro é de ocorrência comum nos trópicos úmidos e sua importância reside, além do seu valor alimentar e forma de consumo, na capacidade de as plantas produzirem em condições consideradas inadequadas para a agricultura tradicional, como pantanais e áreas alagadiças. A habilidade para se desenvolver em locais adversos faz dessa espécie uma cultura de subsistência ideal para áreas onde se utiliza muita mão de obra, especialmente mão-de-obra familiar (HEREDIA ZÁRATE et al., 2004).

Têm sido feitas pesquisas buscando-se conhecer os melhores resíduos orgânicos a serem utilizados durante o ciclo de cultivo do taro, como cobertura morta ou incorporados ao solo, e a viabilidade técnico-econômica do seu uso (HEREDIA ZÁRATE et al., 2004). Dentre as estratégias que caracterizam o manejo da fertilidade do solo destaca-se a escolha do resíduo a ser utilizado na adição ao solo, que é função de sua disponibilidade, variando entre as regiões (HEREDIA ZÁRATE et al., 2007). Além disso, devem-se considerar os efeitos solo-águaplanta que podem causar os resíduos orgânicos segundo o grau de decomposição em que forem adicionados ao solo.

De maneira geral, o uso de resíduos orgânicos favorece a manutenção da matéria orgânica do solo, melhorando suas propriedades físicas, químicas e biológicas. Do ponto de vista físico, promove o aumento da estabilidade de agregados, associado à redução da densidade do solo (ANDREOLA; COSTA; OLSZEVSKI, 2000). Em relação às propriedades químicas, destaca-se o aumento da disponibilidade de nutrientes para as culturas e da capacidade de troca de cátions (CTC), associados à complexação de elementos tóxicos. O resíduo orgânico também auxilia a atividade dos organismos do solo, o que por sua vez resulta em impactos positivos sobre a ciclagem de nutrientes (OLIVEIRA et al., 2008).

Segundo Graciano et al. (2006), as fontes mais comuns de adubo orgânico são representadas pelos adubos verdes, resíduos de culturas, estercos, compostos e outros. A escolha do resíduo vegetal a ser utilizado é função da disponibilidade, variando entre as regiões e a cultura nas quais se fará seu 
emprego. Esses resíduos poderiam ser utilizados para melhorar as propriedades físicas e químicas do solo e, consequentemente, a produtividade de algumas culturas (HEREDIA ZÁRATE et al., 2003).

Em Mato Grosso do Sul, há crescimento muito rápido da avicultura de corte e, na região da GrandeDourados há em torno de 430 aviários em produção e cada um produz em torno de $150 \mathrm{t}^{-1}$ ano de cama-defrango. Portanto, têm aumentado significativamente a quantidade desse resíduo e a necessidade de sua utilização (GRACIANO et al., 2007). Heredia Zárate et al. (2007), estudando a produção e renda de taro Macaquinho, solteiro e consorciado com alface 'Salad Bowl', em solo com cobertura de camade-frango semi-decomposta, observaram que, no geral, as maiores produções de folhas $\left(4,89 \mathrm{t} \mathrm{ha}^{-1}\right)$, rizomas-mãe $\left(6,46 \mathrm{tha}^{-1}\right)$ e rizomas-filho comerciais $\left(15,33 \mathrm{t} \mathrm{ha}^{-1}\right)$ foram obtidas nas plantas sob cultivo solteiro e cultivadas em solo coberto com cama-defrango.

Visando oferecer alternativas de uso da camade-frango e alternativa de cultivo para o sistema de agricultura familiar sustentável, o objetivo deste trabalho foi determinar a produção, a renda bruta e a composição bromatológica dos taros Chinês e Macaquinho, cultivados com diferentes formas de adição ao solo de cama-de-frango semi-decomposta.

\section{Material e Métodos}

O experimento foi realizado no período de setembro de 2007 a abril de 2008, em área experimental da Universidade Federal da Grande Dourados (UFGD), localizada em DouradosMS, em latitude de $22^{\circ} 11^{\prime} 43,7$ 'S, longitude de $54^{\circ} 56^{\prime} 08.5^{\prime \prime} \mathrm{W}$ e altitude de $430 \mathrm{~m}$. O solo do local foi classificado como Latossolo Vermelho distroférrico, textura muito argilosa, e apresentou as seguintes características químicas: M.O. 23,2

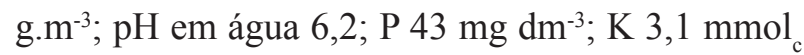
$\mathrm{dm}^{-3}$; Ca 38 mmol $_{\mathrm{c}} \mathrm{dm}^{-3}$; $\mathrm{Mg} 16 \mathrm{mmol}_{\mathrm{c}} \mathrm{dm}^{-3}$; H+Al $50 \mathrm{mmol}_{\mathrm{c}} \mathrm{dm}^{-3}$; CTC 107,1 $\mathrm{mmol}_{\mathrm{c}} \mathrm{dm}^{-3}$ e saturação por bases (V) $53 \%$. Na parte física, os resultados da análise granulométrica mostraram que o solo era composto por $8 \%$ de areia grossa, $13 \%$ de areia fina, $16 \%$ de silte e $63 \%$ de argila.

Os fatores em estudo foram clones de taro (Chinês e Macaquinho) e formas de adição ao solo da cama-de-frango semi-decomposta (solo sem cama-de-frango; com $10 \mathrm{t} \mathrm{ha}^{-1}$ de cama-de-frango em cobertura; com $10 \mathrm{t} \mathrm{ha}^{-1}$ de cama-de-frango incorporada e com $5 \mathrm{t} \mathrm{ha}^{-1}$ de cama-de-frango em cobertura $+5 \mathrm{t} \mathrm{ha}^{-1}$ incorporada). Os tratamentos foram arranjados em esquema fatorial $2 \times 4$, no delineamento experimental de blocos casualizados, com cinco repetições. As parcelas tiveram área total de $6,0 \mathrm{~m}^{2}$ (1,5 m de largura por 4,0 $\mathrm{m}$ de comprimento), sendo a área útil em canteiro de 1,0 $\mathrm{m}$ de largura. O cultivo foi em fileiras duplas, espaçadas de $60 \mathrm{~cm}$ e o espaçamento entre plantas foi de $20 \mathrm{~cm}$, perfazendo população de 66.000 plantas $\mathrm{ha}^{-1}$. A análise química da cama-de-frango utilizada no experimento apresentou os seguintes teores: C orgânico 205,6 $\mathrm{g} \mathrm{kg}^{-1}$, P total $28,5 \mathrm{~g} \mathrm{~kg}^{-1}$, $\mathrm{K}$ total $24,3 \mathrm{~g} \mathrm{~kg}^{-1}$, $\mathrm{N}$ total $18,7 \mathrm{~g} \mathrm{~kg}^{-1}$ e relação $\mathrm{C} / \mathrm{N}$ 11,0 .

O terreno foi preparado com aração, gradagem e em seguida os canteiros foram levantados com rotoencanteirador. Antes da segunda passagem do rotoencanteirador foi efetuada a incorporação da cama-de-frango, nas respectivas parcelas com esse tratamento.

Para o plantio, foram abertos sulcos de $0,05 \mathrm{~m}$ de largura $\mathrm{x}$ 0,05 $\mathrm{m}$ de profundidade. As mudas foram rizomas-filho inteiros (HEREDIA ZÁRATE et al., 2003) colocadas no fundo do sulco, empurradas em profundidade, com a gema apical para cima, e cobertos com o solo extraído na abertura dos sulcos. A camada de solo acima da gema apical era de $\pm 2,0 \mathrm{~cm}$. Imediatamente após o plantio foi efetuada a cobertura do solo com a cama-de-frango, a lanço, nas parcelas correspondentes a esse tipo de tratamento.

Durante o ciclo da cultura, as irrigações foram feitas utilizando o sistema de aspersão, com 
turnos de regas a cada dois dias e nos dois últimos meses (março e abril) foram feitas duas vezes por semana. As plantas infestantes foram controladas por arranquios manuais dentro dos canteiros e com capina com enxada entre os canteiros, quando apresentavam $\pm 5,0 \mathrm{~cm}$ de altura.

Visando conhecer melhor o comportamento dos clones optou-se por duas colheitas. A primeira colheita programada inicialmente e que seria feita quando as plantas apresentassem em torno de 50\% de sinais de senescência da parte foliar, com folhas externas amarelas, murchas e secas (HEREDIA ZÁRATE; VIEIRA; REGO, 2006b) e que coincidiu com 183 dias após o plantio, colhendose as plantas contidas na metade da área de cada parcela. A segunda colheita, foi realizada quando as plantas da outra metade da área das diferentes parcelas apresentavam em torno de $70 \%$ de sinais de senescência. As características avaliadas foram a altura das plantas e as massas de matérias fresca e seca de parte aérea (limbos + pecíolos) e as produções de rizomas-mãe e de rizomas-filho comerciais (maior que $25 \mathrm{~g}$ ) e não-comerciais (menores que $25 \mathrm{~g}$ ), utilizando pesagem em balança analítica digital com 0,1 g de precisão). Para se determinar a massa de matéria seca, as folhas e os rizomas foram cortados em fatias finas e colocados em sacos de papel, para secagem em estufa com circulação forçada de ar, a $65^{\circ} \mathrm{C} \pm 2{ }^{\circ} \mathrm{C}$, até apresentarem massa constante.

As variáveis avaliadas foram submetidas à análise de variância e, quando detectou-se significância pelo teste de $\mathrm{F}$, as médias para clones foram comparadas pelo teste $\mathrm{F}$ e para formas de adição ao solo de cama-de-frango pelo teste de Tukey, ao nível de 5\% de probabilidade.

Amostras de matéria seca das folhas, rizomasmãe e rizomas-filho, obtidas da mistura das matérias secas das repetições de cada tratamento, foram enviadas ao Laboratório de Tecnologia de Alimentos da Universidade Federal de Mato Grosso do Sul, em Campo Grande-MS, para realização das análises bromatológicas. As determinações de umidade foram realizadas somente uma vez e as análises dos outros componentes foram em triplicata, com apresentação das médias e dos seus desvios padrões. As análises de umidade, resíduos minerais fixos, lipídios totais e açúcares totais (glicídios redutores e não redutores) foram realizadas pelos métodos descritos nas normas analíticas do Instituto Adolfo Lutz (BRASIL, 2005) e as análises de proteínas, pelo método descrito pela Association Official Analytical Chemists (AOAC, 1984).

A validação econômica dos resultados foi realizada mediante a determinação da renda bruta e, para isso utilizaram-se as produções dos rizomas-filho comerciais dos taros Chinês e Macaquinho em função das formas de adição ao solo da cama-de-frango. Para o cálculo da renda bruta, foram pesquisados os preços pagos aos produtores de Dourados pelo kilograma de rizomasfilhos comerciais ( $\mathrm{R} \$ 2,50 \mathrm{~kg}^{-1}$ ) e posteriormente, efetuaram-se as conversões por hectare.

\section{Resultados e Discussão}

Os resultados obtidos para as diferentes características avaliadas nas plantas de taro na primeira colheita, efetuada aos 183 dias após o plantio, não foram influenciados significativamente pela interação clone e cama-de-frango (CF) nem pela forma de adição da CF mas observaram-se diferenças significativas relacionadas com os clones (Tabela 1). Esses resultados indicam que houve respostas modificativas que adaptaram as plantas às condições ambientes, durante o seu período de crescimento (LARCHER, 2006). 
Tabela 1. Altura de plantas e massas frescas e secas de rizomas-mãe (RM), rizomas-filho comerciais (RFC) e rizomasfilho não-comerciais (RFNC) dos taros 'Chinês' e 'Macaquinho', em resposta às formas de adição ao solo da camade-frango semidecomposta, aos 183 e 211 dias após o plantio. Dourados, UFGD, 2007-2008.

\begin{tabular}{|c|c|c|c|c|c|c|c|c|c|c|}
\hline \multirow{2}{*}{$\begin{array}{l}\text { Fatores em } \\
\text { estudo }\end{array}$} & \multirow{2}{*}{ DAP } & \multirow{2}{*}{$\begin{array}{l}\text { Altura de } \\
\text { plantas } \\
(\mathrm{cm})\end{array}$} & \multicolumn{4}{|c|}{ Massa fresca $\left(\mathrm{t} \mathrm{ha}^{-1}\right)$} & \multicolumn{4}{|c|}{ Massa seca $\left(\mathrm{t} \mathrm{ha}^{-1}\right)$} \\
\hline & & & Folha & $\mathrm{RM}$ & RFC & RFNC & Folha & $\mathrm{RM}$ & $\mathrm{RFC}$ & RFNC \\
\hline \multicolumn{11}{|c|}{ Clones } \\
\hline \multirow{2}{*}{ Chinês } & 183 & $76,94 \mathrm{a}$ & $29,11 \mathrm{a}$ & $5,86 \mathrm{~b}$ & $16,03 \mathrm{~b}$ & $8,60 \mathrm{a}$ & $1,58 \mathrm{a}$ & $1,23 \mathrm{a}$ & $3,50 \mathrm{a}$ & $1,77 \mathrm{a}$ \\
\hline & 211 & $72,33 \mathrm{a}$ & $10,84 \mathrm{a}$ & $4,84 \mathrm{a}$ & $18,60 \mathrm{~b}$ & $4,65 \mathrm{a}$ & $0,80 \mathrm{a}$ & $1,15 \mathrm{a}$ & $4,62 \mathrm{a}$ & $1,11 \mathrm{a}$ \\
\hline \multirow{2}{*}{ Macaquinho } & 183 & $62,99 \mathrm{~b}$ & $11,13 \mathrm{~b}$ & $7,22 \mathrm{a}$ & $27,14 \mathrm{a}$ & $6,93 \mathrm{a}$ & $0,84 \mathrm{~b}$ & $0,97 \mathrm{a}$ & $3,95 \mathrm{a}$ & $1,02 \mathrm{a}$ \\
\hline & 211 & $56,95 \mathrm{~b}$ & $2,95 \mathrm{~b}$ & $5,71 \mathrm{a}$ & $25,00 \mathrm{a}$ & $5,54 \mathrm{a}$ & $0,22 \mathrm{a}$ & $0,86 \mathrm{a}$ & $4,24 \mathrm{a}$ & $0,87 \mathrm{a}$ \\
\hline \multicolumn{11}{|c|}{ Formas de adição da cama-de-frango } \\
\hline \multirow{2}{*}{ Sem } & 183 & $66,53 \mathrm{a}$ & $21,11 \mathrm{a}$ & $6,02 \mathrm{a}$ & $19,55 \mathrm{a}$ & $7,29 \mathrm{a}$ & $1,38 \mathrm{a}$ & $1,07 \mathrm{a}$ & $3,50 \mathrm{a}$ & $1,31 \mathrm{a}$ \\
\hline & 211 & $64,40 \mathrm{a}$ & $6,81 \mathrm{a}$ & $4,61 \mathrm{~b}$ & $18,43 \mathrm{a}$ & $4,65 \mathrm{a}$ & $0,45 \mathrm{a}$ & $0,87 \mathrm{a}$ & $4,09 \mathrm{a}$ & $0,93 \mathrm{a}$ \\
\hline \multirow{2}{*}{ Cobertura (C) } & 183 & $69,10 \mathrm{a}$ & $18,16 \mathrm{a}$ & $6,94 \mathrm{a}$ & $21,69 \mathrm{a}$ & $8,35 \mathrm{a}$ & $1,03 \mathrm{a}$ & $1,14 \mathrm{a}$ & $3,73 \mathrm{a}$ & $1,39 \mathrm{a}$ \\
\hline & 211 & $61,77 \mathrm{a}$ & $6,36 \mathrm{a}$ & $5,64 \mathrm{ab}$ & $24,20 \mathrm{a}$ & $5,54 \mathrm{a}$ & $0,51 \mathrm{a}$ & $1,16 \mathrm{a}$ & $5,07 \mathrm{a}$ & $1,03 \mathrm{a}$ \\
\hline \multirow{2}{*}{$\begin{array}{l}\text { Incorporada } \\
\text { (I) }\end{array}$} & 183 & $70,77 \mathrm{a}$ & $19,91 \mathrm{a}$ & $6,04 \mathrm{a}$ & $20,59 \mathrm{a}$ & $8,38 \mathrm{a}$ & $1,19 \mathrm{a}$ & $0,99 \mathrm{a}$ & $3,52 \mathrm{a}$ & $1,60 \mathrm{a}$ \\
\hline & 211 & $63,59 \mathrm{a}$ & $6,75 \mathrm{a}$ & $4,37 \mathrm{~b}$ & $20,44 \mathrm{a}$ & $4,16 \mathrm{a}$ & $0,58 \mathrm{a}$ & $0,85 \mathrm{a}$ & $4,07 \mathrm{a}$ & $0,92 \mathrm{a}$ \\
\hline \multirow{2}{*}{$\mathrm{C}+\mathrm{I}$} & 183 & $73,47 \mathrm{a}$ & $21,29 \mathrm{a}$ & $7,16 \mathrm{a}$ & $21,52 \mathrm{a}$ & $7,06 \mathrm{a}$ & $1,24 \mathrm{a}$ & $1,22 \mathrm{a}$ & $4,15 \mathrm{a}$ & $1,29 \mathrm{a}$ \\
\hline & 211 & $68,82 \mathrm{a}$ & $7,66 \mathrm{a}$ & $6,49 \mathrm{a}$ & $24,14 \mathrm{a}$ & $6,03 \mathrm{a}$ & $0,49 \mathrm{a}$ & $1,15 \mathrm{a}$ & $4,51 \mathrm{a}$ & $1,10 \mathrm{a}$ \\
\hline \multirow{2}{*}{ C.V.\% } & 183 & 14,48 & 34,21 & 25,24 & 39,77 & 19,58 & 33,58 & 31,09 & 36,19 & 15,97 \\
\hline & 211 & 20,07 & 37,89 & 28,95 & 31,07 & 40,37 & 43,93 & 34,89 & 34,72 & 42,29 \\
\hline
\end{tabular}

Médias seguidas pelas mesmas letras nas colunas, dentro de clones e de formas de adição da cama-de-frango, não diferem entre si pelos testes $\mathrm{F}$ e Tukey, respectivamente, a $\%$ de probabilidade.

Fonte: Elaboração dos autores.

A altura das plantas, a massa fresca e seca das folhas e as massas frescas dos rizomas-mãe (RM) e dos rizomas-filhos comerciais (RFC) foram influenciadas significativamente pelos clones, na colheita realizada aos 183 dias após o plantio (Tabela 1). O clone Chinês obteve 13,95 cm; $17,98 \mathrm{t} \mathrm{ha}^{-1}$ e $0,74 \mathrm{t} \mathrm{ha}^{-1}$, respectivamente, a mais de altura de plantas, de massa fresca de folhas e de massa seca de folhas em comparação ao clone Macaquinho. No entanto, o clone Macaquinho superou em 1,36 tha ${ }^{-1}$ e 11,11 $\mathrm{t} \mathrm{ha}^{-1}$ de massa fresca de RM e RFC, respectivamente, às do Chinês. Resultados semelhantes foram obtidos por Heredia Zárate et al. (2003), avaliando as produções de massa fresca das plantas dos clones de taro Chinês e Macaquinho, cultivadas sob cinco doses de camade-frango de corte semidecomposta, incorporada ao solo. Esses autores observaram que a produção de massa fresca de RM (4,56 t ha-1), RFC (15,85 tha$\left.{ }^{1}\right)$ e $\operatorname{RFNC}\left(1,80 \mathrm{t} \mathrm{ha}^{-1}\right)$ do clone Macaquinho foi
$1,8 \mathrm{t} \mathrm{ha}^{-1}$ e 7,32 $\mathrm{t} \mathrm{ha}^{-1}$ e $0,17 \mathrm{t} \mathrm{ha}^{-1}$, respectivamente, maior que as do Chinês. Os resultados observados no presente trabalho são também corroborados pelos resultados de Heredia Zárate et al. (2004), que estudando a forma de adição ao solo da camade-frango de corte semidecomposta para produção de taro, observaram que a massa fresca de RM do taro Macaquinho (17,4 tha-1) foi significativamente maior quando comparada às dos clones Chinês $(9,9$ t ha $\left.{ }^{-1}\right)$, Japonês $\left(10,0 \mathrm{t} \mathrm{ha} \mathrm{a}^{-1}\right), \mathrm{Cem} / \mathrm{Um}\left(9,5 \mathrm{t} \mathrm{ha}^{-1}\right) \mathrm{e}$ $\operatorname{Branco}\left(7,8 \mathrm{tha}^{-1}\right)$.

Os resultados obtidos para os parâmetros avaliados nas plantas do taro Chinês e do Macaquinho mostraram que, nas condições em que foi conduzido o experimento, as plantas do Chinês apresentavam maiores alturas de plantas e de massas frescas de folhas e de RFNC e menores massas frescas de RM e RFC, em relação às do Macaquinho. O acontecido é coerente com a 
afirmação de Heredia Zárate et al. (2004), de que cultivares de taro diferem grandemente com relação ao tempo para alcançarem a maturidade e que as plantas que apresentam crescimento exuberante podem não produzir muito bem, uma vez que podem ter que gastar muitos fotoassimilados com a manutenção da parte aérea e, assim, terem retardadas a maturidade e o início do processo de senescência das folhas mais velhas, com atraso na translocação dos fotoassimilados de reserva para os rizomas. No trabalho de Heredia Zárate et al. (2009) é relatado que os açúcares sintetizados no limbo do taro são translocados para os rizomas, passando por um 'armazenamento temporário' no pecíolo. Dessa forma, o armazenamento de reservas nos rizomas é altamente dependente da integridade das estruturas aéreas (limbo e pecíolo), e qualquer alteração morfofisiológica dessas poderá afetar a síntese, quantidade e velocidade de translocação dos assimilados, repercutindo no crescimento e produtividade de rizomas (HEREDIA ZÁRATE et al., 2009).

Na colheita realizada aos 211 DAP, também não foi observada interação significativa entre os clones e as formas de adição ao solo da CF. A altura das plantas e as produções de massas fresca de folha e RFC foram significativamente dependentes dos clones e independentes da forma de adição ao solo da $\mathrm{CF}$, exceto as produções de massa fresca de RM, com efeito significativo da CF (Tabela 1). Isso porque os clones de taro diferem com relação ao tempo para alcançar a maturidade e com a quantidade de fotossintatos armazenados nas folhas (limbos e pecíolos), que podem ser translocados para os RM, quando as folhas iniciam a senescência (HEREDIA ZÁRATE et al., 2003).

O clone Chinês foi $15,38 \mathrm{~cm}$ e $7,89 \mathrm{t} \mathrm{ha}^{-1}$ maiores na altura de plantas e na massa fresca de folhas, respectivamente, em comparação as do taro 'Macaquinho', que por sua vez, obteve 6,4 t ha-1 a mais de massa fresca de RFC. Heredia Zárate, Vieira e Hiane (2006a), avaliando a produção e composição nutritiva de taro em função do propágulo, em solo hidromórfico do Pantanal Sul-Matogrossense, também observaram que o clone Chinês obteve 5,4 $\mathrm{cm}$ de altura e 0,52 $\mathrm{t} \mathrm{ha}^{-1}$ de massa fresca de folhas a mais que as do taro 'Macaquinho'. Esses resultados confirmam a citação de Heredia Zárate et al. (2004) de que cultivares de taro diferem grandemente em relação ao tempo para alcançarem a maturidade fisiológica e, por isso, pode considerar-se o taro Macaquinho como de ciclo precoce e o Chinês como tardio.

As produções de massa fresca de RM foram influenciadas pela forma de adição ao solo da CF, sendo que esse resíduo orgânico quando utilizado em cobertura + incorporado induziu aumento de $2,12 \mathrm{t} \mathrm{ha}^{-1}$ em relação à obtida no solo com a $\mathrm{CF}$ incorporada, que foi estatisticamente a pior (Tabela 1). Segundo Heredia Zárate et al. (2004, 2007) e Carvalho et al. (2005), provavelmente a cama-de-frango, quando utilizada em cobertura, deve ter contribuído na regulação da temperatura e na manutenção da umidade do solo, além de ter reduzido a perda de nutrientes por lixiviação e melhorado os atributos microbiológicos do solo. Ao ser incorporada ao solo, pode ter melhorado as propriedades físicas e químicas do solo, a movimentação e retenção de água, a difusão de gases da solução do solo e a distribuição do sistema radicular, acarretando em aumento na produtividade da planta. Além disso, esses resultados mostramse coerentes com a hipótese de que a partição dos fotoassimilados é função do genótipo e das relações fonte-dreno, em que a eficiência de conversão fotossintética, dentre outros fatores, pode ser alterada pelas condições de solo, clima e estádio fisiológico da cultura (TOLENTINO JÚNIOR et al., 2002). As diferenças entre as produções de rizomas mãe aos 183 e 211 DAP e falta de diferenças nas produções de RFC sugerem que os rizomas-mãe ainda não tinham alcançado a maturidade e o máximo crescimento; que houve provável aumento da translocação dos fotoassimilados da parte aérea para os RM e destes diretamente para os rizomasfilho ou que houve equilíbrio de translocação no 
tempo, entre a parte aérea e os rizomas (HEREDIA ZÁRATE et al., 2012).

As produções de massa fresca de folhas do taro 'Chinês' nas duas colheitas (Tabela 1) foram maiores que as do 'Macaquinho', mas as produções de RFC foram maiores no 'Macaquinho'. Essas diferenças nas produções de massa fresca de folhas e de RFC entre os dois clones corroboram as hipóteses citados por Heredia Zárate et al. (2003), de que as folhas são locais de armazenamento temporário de fotossintatos e, à medida que aumenta a senescência delas, deve existir aumento da translocação dos fotossintatos das folhas para os RM e desses diretamente para os RF.

As massas secas de folhas, RM, RFC e RFNC não foram influenciadas significativamente pelos fatores em estudo. Fato que pode dever-se às variações porcentuais de massa seca em relação à massa fresca produzida pelas plantas de cada clone, em cada época de colheita e que influenciou para a falta de significância produtiva observada. Assim, na colheita aos 183 dias, as porcentagens de massa seca de folhas, RM, RFC e RFNC das plantas do Chinês foram de 5,43; 20,98; 21,83 e 20,58\%, respectivamente e as das plantas do Macaquinho foram 7,$55 ; 13,43 ; 14,55$ e 14,72\%. Isso confirma o exposto por Larcher (2006) sobre a capacidade das plantas de uma determinada espécie poderem autorregular-se, com base no equilíbrio das relações de interferência e porque, embora a planta inteira seja autotrófica, seus órgãos individuais são heterotróficos, dependendo uns dos outros para obter nutrientes e fotossintatos (LARCHER, 2006).

$\mathrm{O}$ fato da porcentagem de massa seca de folhas das plantas do taro 'Chinês' aos 183 dias (5,43\%) ter sido menor que aquela aos 211 dias (7,38\%) e as das plantas do taro 'Macaquinho' terem sido semelhantes $(7,55$ e $7,46 \%)$ corroboram na classificação comportamental do taro 'Macaquinho' como de ciclo precoce e o 'Chinês' como tardio.

Os valores calculados para a renda bruta (Tabela 2) mostraram que os taros Chinês e Macaquinho devem ser cultivados em solo com adição da CF em cobertura + incorporada. Em termos econômicos, a melhor época de colheita do Macaquinho foi aos 183 DAP, porque teria gerado renda bruta de $\mathrm{R} \$$ $81.175,00$ e teria superado em $\mathrm{R} \$ 800,00$ à maior renda obtida com o próprio Macaquinho colhido aos 211 DAP e superado em R \$ 39.750,00 e R\$ 29.950,00 às maiores rendas obtidas com o Chinês, nas colheitas aos 183 e 211 DAP. A melhor época de colheita do Chinês foi aos 211 DAP porque teria gerado renda de $\mathrm{R} \$ 51.225,00$ e superado em $\mathrm{R} \$ 9.800,00$ à renda obtida aos 183 DAP. Isso mostra que a análise econômica deve ser feita para se conhecer em detalhes a estrutura produtiva da atividade e realizar as alterações necessárias ao aumento de sua eficiência (PEREZ JÚNIOR; OLIVEIRA; COSTA, 2006).

Após secagem das folhas, rizomas-mãe e rizomas-filho os maiores teores de umidade foram das amostras dos RM, especialmente daqueles originados de plantas cultivadas em solo onde a $\mathrm{CF}$ foi adicionada em cobertura + incorporada (Tabela 3), com o máximo valor correspondente aos RM do taro 'Chinês' $(10,40 \%)$. Os menores teores foram dos rizomas-filho - RF do clone Macaquinho, praticamente independente da forma de incorporação da CF. Resultados semelhantes foram obtidos por Heredia Zárate, Vieira e Hiane (2006a), que estudando a produção e composição nutritiva de taro em função do propágulo, em solo hidromórfico do pantanal sul-mato-grossense observaram que para os clones produzidos em Dourados, os maiores teores de umidade foram do RM e RF do taro Chinês $(9,23 \%$ e 9,40\%) em comparação com o 'Macaquinho' (7,67\% e 8,70\%). Esses resultados de umidade nos RM mostram que houve provável relação com a composição da massa seca, no qual deve ter havido maior teor de algum componente higroscópico que deve ter induzido absorção de água do ar ou pela composição dos RM que dificultaram a perda de água. 
Tabela 2. Produção e estimativa da renda bruta dos rizomas-filho comerciais (RFC) dos taros 'Chinês' e 'Macaquinho' em resposta às formas de adição ao solo da cama-de-frango semidecomposta, aos 183 e aos 211 dias após o plantio DAP. Dourados, UFGD, 2007-2008.

\begin{tabular}{cccccc}
\hline \multirow{2}{*}{ Clones } & $\begin{array}{c}\text { Formas de adição da } \\
\text { cama-de-frango }\end{array}$ & \multicolumn{2}{c}{$\begin{array}{c}\text { Produção RFC } \\
\left(\mathrm{kg} \mathrm{ha}^{-1}\right)\end{array}$} & \multicolumn{2}{c}{$\begin{array}{c}\text { Renda Bruta } \\
\text { (R\$) }\end{array}$} \\
\cline { 3 - 6 } & Sem & 183 DAP & 211 DAP & 183 DAP & 211 DAP \\
\hline \multirow{4}{*}{ Chinês } & Cobertura (C) & 15.650 & 17.880 & $39.125,00$ & $44.700,00$ \\
& Incorporada (I) & 17.220 & 19.110 & $36.750,00$ & $47.775,00$ \\
& C + I & 16.570 & 16.900 & $43.050,00$ & $42.250,00$ \\
\multirow{4}{*}{ Macaquinho } & Sem & 23.460 & 23.490 & $41.425,00$ & $51.225,00$ \\
\hline & Cobertura (C) & 28.670 & 29.280 & $58.650,00$ & $59.750,00$ \\
& Incorporada (I) & 23.970 & 23.990 & $71.675,00$ & $73.200,00$ \\
& C + I & 32.470 & 32.150 & $89.925,00$ & $59.975,00$ \\
& & &
\end{tabular}

*Preço pago ao produtor dos taros Chinês e Macaquinho em Dourados-MS, em julho de $2013=\mathrm{R} \$ 2,50 \mathrm{~kg}$.

Fonte: Elaboração dos autores.

Os teores de resíduos minerais fixos - RMF (16,73\% a $21,08 \%)$, lipídeos $(2,79 \%$ a $4,26 \%)$ e proteínas $(8,98 \%$ a $12,28 \%)$ foram maiores nas folhas, sendo que as amostras provenientes do clone Chinês apresentaram maiores valores, com exceção para RMF quando se utilizou a CF incorporada e para proteínas no tratamento $\mathrm{CF}$ em cobertura + incorporado, em que o clone Macaquinho obteve os maiores valores $23,35 \%$ e $12,28 \%$, respectivamente. Em função desses resultados obtidos sugere-se a procura de uma alternativa de uso das folhas dos dois clones. Contudo, segundo Monteiro (2002), tanto os rizomas quanto as folhas de quase todas as variedades de taro, dependendo das condições de cultivo, especialmente em relação à água, não devem ser ingeridos crus, pois podem apresentar, em sua composição, um princípio picante à base de oxalato de cálcio, que produz irritação nas mucosas da boca e garganta.
Considerando os teores de açúcares totais e seus correspondentes valores calóricos totais - VTC foram maiores nos rizomas-mãe dos dois clones, no entanto, o taro 'Chinês' apresentou melhores resultados, sendo que no tratamento sem cama-defrango obtiveram-se os maiores valores, 77,98\% e $332,48 \mathrm{kcal} 100 \mathrm{~g}^{-1}$, respectivamente. As folhas apresentaram os menores teores de açúcares totais. Esses resultados são coerentes com a hipótese de que a partição dos fotoassimilados é função do genótipo e das relações fonte-dreno, em que a eficiência de conversão fotossintética, dentre outros fatores, pode ser alterada pelas condições de solo, clima e estádio fenológico da cultura (TOLENTINO JÚNIOR et al., 2002). 


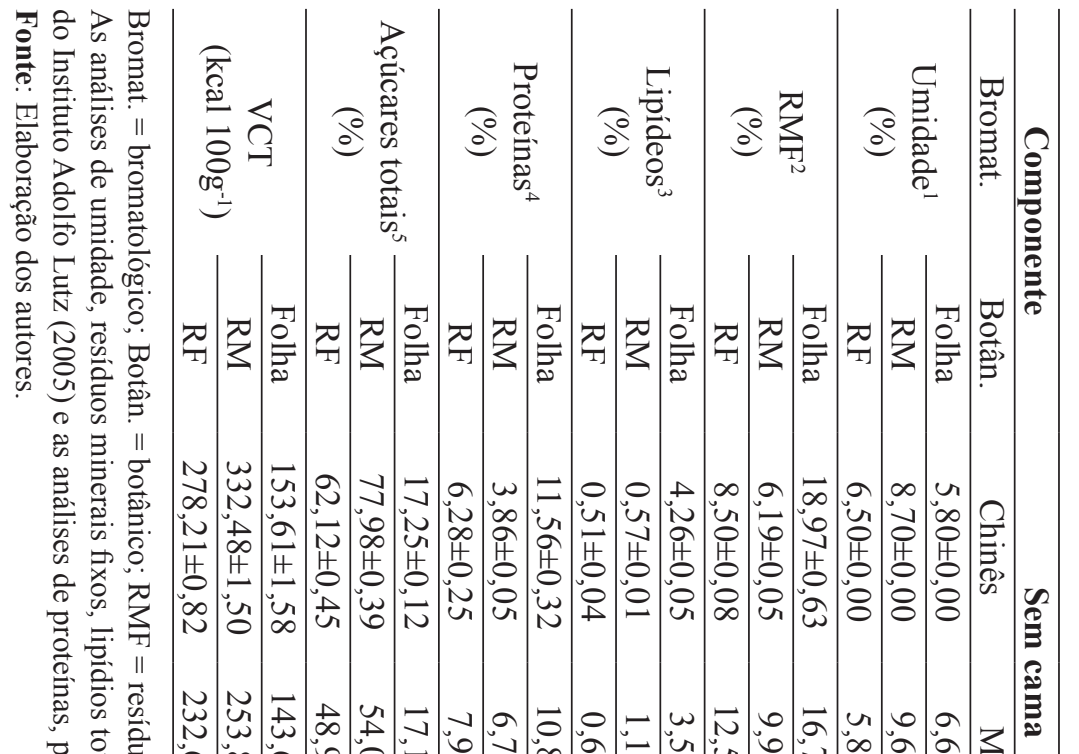

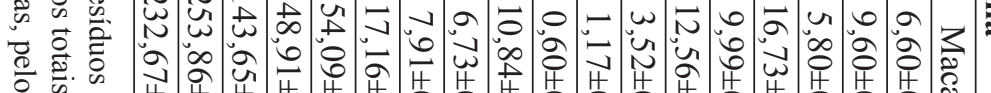

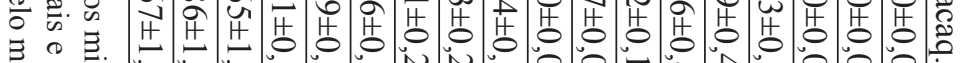

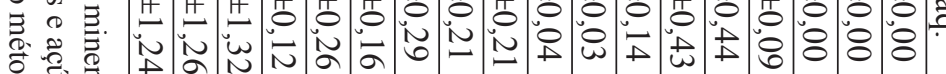

定

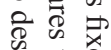

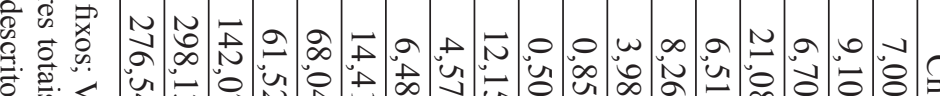

Oे.

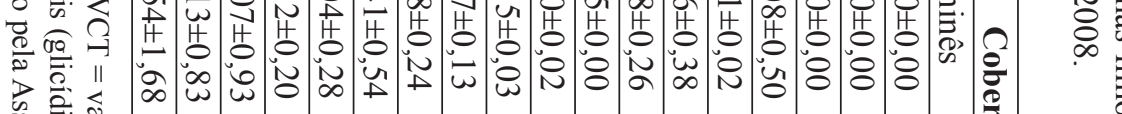

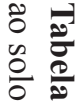

ק्र

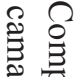

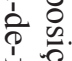

劳

品 寻

忿

空.

$\delta$

莫

అ

苍

号

$\Omega$

용

客

웅

营.

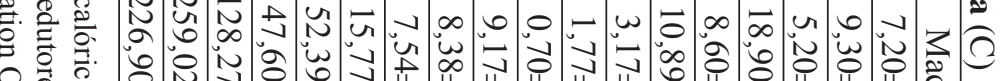

象空

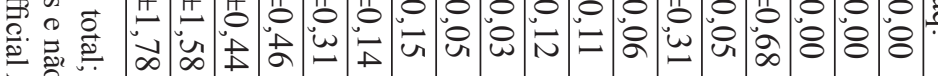

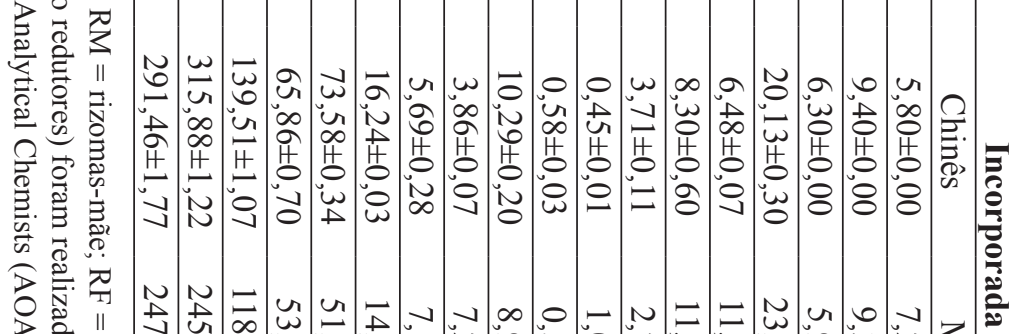

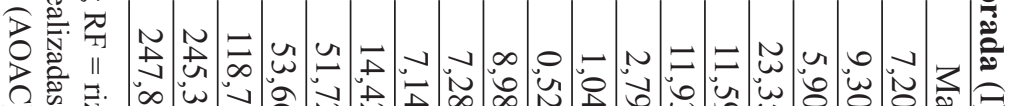

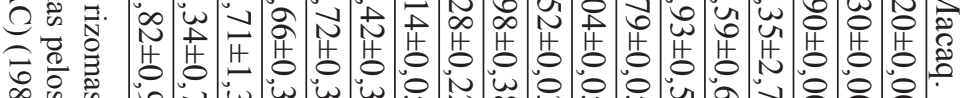

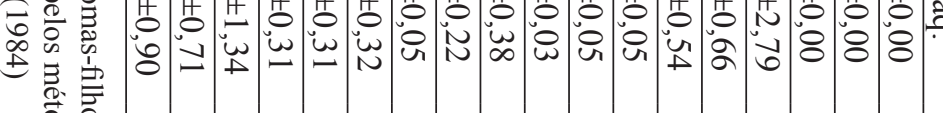

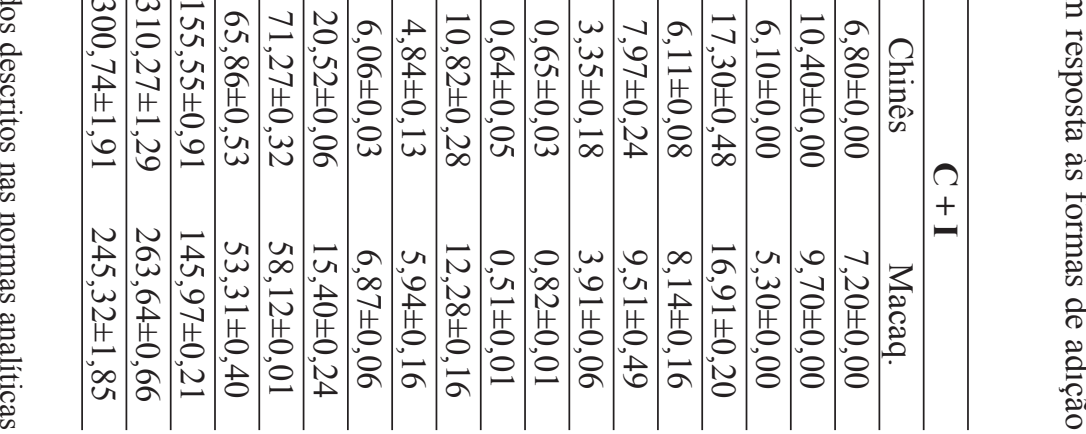




\section{Conclusões}

As plantas do taro Macaquinho foram precoces e mais produtivas que as do 'Chinês'. Para obter maior renda bruta deve-se cultivar o taro Macaquinho com cama-de-frango em cobertura $\left(5 \mathrm{t} \mathrm{ha}^{-1}\right)+$ incorporada $\left(5 \mathrm{t} \mathrm{ha}^{-1}\right)$ e realizar a colheita aos 183 dias após o plantio. Os rizomas-mãe e rizomas-filho do taro 'Chinês' apresentaram melhores características nutritivas do que os do 'Macaquinho', quando cultivados sem cama-de-frango.

\section{Agradecimentos}

À FUNDECT-MS, pela bolsa de mestrado à segunda autora e apoio financeiro e ao CNPq, pelas bolsas de Pesquisa e de Iniciação Científica.

\section{Referências}

ANDREOLA, F.; COSTA, L. M.; OLSZEVSKI, N. Influência da cobertura vegetal de inverno e da adubação orgânica e, ou, mineral sobre as propriedades físicas de uma Terra Roxa Estruturada. Revista Brasileira de Ciência do Solo, Viçosa, MG, v. 24, n. 3, p. 857-865, 2000.

ASSOCIATION OF OFFICIAL ANALYTICAL CHEMISTS - AOAC. Official methods of analysis of AOAC. Washington. 1984. 988 p.

BRASIL. Ministério da Saúde. Agência Nacional de Vigilância Sanitária. Métodos físico-químicos para análises de alimentos. Ministério da Saúde, Brasília, 2005. 1018 p.

CARVALHO, J. E.; ZANELLA, F.; MOTA, J. H.; LIMA, A. L. S. Cobertura morta do solo no cultivo de alface cv. Regina 2000, em Ji-Paraná/RO. Ciência e Agrotecnologia, Lavras, v. 29, n. 5, p. 935-939, 2005.

GRACIANO, J. D.; HEREDIA ZÁRATE, N. A.; VIEIRA, M. C.; ROSA, Y. B. C. J.; SEDIYAMA, M. A. N. Espaçamento entre fileiras e entre plantas na produção da mandioquinha-salsa 'Branca'. Ciência e Agrotecnologia, Lavras, v. 31, n. 6, p. 1688-1695, 2007.

GRACIANO, J. D.; HEREDIA ZÁRATE, N. A.; VIEIRA, M. C.; ROSA, Y. B. C. J.; SEDIYAMA, M. A. N.; RODRIGUES, E. T. Efeito da cobertura do solo com cama-de-frango semidecomposta sobre dois clones de mandioquinha-salsa. Acta Scientiarum. Agronomy, Maringá, v. 28, n. 3, p. 365-371, 2006.
HEREDIA ZÁRATE, N. A.; VIEIRA, M. C.; GIULIANI, A. R.; HELMICH, M.; PONTIM, B. C. A.; PEZZONI FILHO, J. C. Produção e renda de taro Macaquinho, solteiro e consorciado com alface 'Salad Bowl', em solo com cobertura de cama-de-frango semidecomposta. Semina: Ciências Agrárias, Londrina, v. 28, n. 4, p. 563570, 2007.

HEREDIA ZÁRATE, N. A.; VIEIRA, M. C.; GRACIANO, J. D.; GIULIANI, A. R.; HELMICH, M.; GOMES, H. E. Produção e renda bruta de quatro clones de taro cultivados em Dourados, Estado do Mato Grosso do Sul. Acta Scientiarum. Agronomy, Maringá, v. 31, n. 2, p. 301-305, 2009.

HEREDIA ZÁRATE, N. A.; VIEIRA, M. C.; HIANE, P. A. Produção e composição nutritiva de taro em função do propágulo, em solo hidromórfico do Pantanal Sul-MatoGrossense. Semina: Ciências Agrárias, Londrina, v. 27, n. 3, p. 357-362, 2006a.

HEREDIAZÁRATE, N. A.; VIEIRA, M. C.; OLIVEIRA, A. C. P.; LIMA, A. A. Produção e renda bruta de dois cultivares de taro, em cultivo solteiro e consorciado com alface. Semina: Ciências Agrárias, Londrina, v. 26, n. 3, p. 283-290, 2005.

HEREDIA ZÁRATE, N. A.; VIEIRA, M. C.; ROSA JUNIOR, E. J.; ALVES, J. C. Cama-de-frango de corte semidecomposta na produção dos taros Chinês e Macaquinho. Acta Scientiarum. Agronomy, Maringá, v. 25, n. 1, p. 177-181, 2003.

HEREDIA ZÁRATE, N. A.; VIEIRA, M. C.; ROSA JUNIOR, E. J.; SILVA, C. G. Forma de adição ao solo da cama-de-frangos de corte semidecomposta para produção de taro. Pesquisa Agropecuária Tropical, Goiânia, v. 34, n. 2, p. 111-117, 2004.

HEREDIA ZÁRATE, N. A.; VIEIRA, M. C.; TABALDI, L. A.; GASSI, R. P.; KUSANO, A. M.; MAEDA, A. K. M. Produção agroeconômica de taro em função do número de amontoas. Semina: Ciências Agrárias, Londrina, v. 33, n. 4, p. 1673-1680, 2012.

HEREDiA ZÁRATE, N. A.;VIEIRA, M. C.; REGO, N. H. Produtividade de clones de taro em função da população de plantas na época seca do pantanal SulMato-Grossense. Pesquisa Agropecuária Tropical, Goiânia, v. 36, n. 2, p. 141-143, 2006 b.

LARCHER, W. Ecofisiologia vegetal. São Paulo: Rima Artes e Textos, 2006. $531 \mathrm{p}$.

MONTEIRO, D. A. Manejo da cultura do taro. In: CARMO, C. A. Situação atual e perspectivas do taro no Estado de São Paulo. Vitória: INCAPER, 2002. 77 p. 
OLIVEIRA, F. L.; GUERRA, J. G. M.; ALMEIDA, D. L.; RIBEIRO, R. L. D.; SILVA, E. D.; SILVA, V. V.; ESPINDOLA, J. A. A. Desempenho de taro em função de doses de cama de aviário, sob sistema orgânico de produção. Horticultura Brasileira, Brasília, v. 26, n. 2, p. 149-153, 2008.

PEREZ JÚNIOR, J. H.; OLIVEIRA, L. M.; COSTA, R. G. Gestão estratégica de custos. 5. ed. São Paulo: Atlas, 2006. $378 \mathrm{p}$.

SILVA, D. J.; QUEIROZ, C. Análise de alimentos: métodos químicos e biológicos. Viçosa: Universidade Federal de Viçosa, 2002. 235 p.
TOLENTINO JÚNIOR, C. F.; HEREDIA ZÁRATE, N. A.; VIEIRA, M. C.; MENDONÇA, P. S. M. Produção da mandioquinha-salsa consorciada com alface e beterraba. Acta Scientiarum: Agronomy, Maringá, v. 4, n. 5, p. 1447-1454, 2002.

VILPOUX, O. Produção e uso do amido. In: CEREDA, M. P. (Ed.). Propriedades gerais do amido. São Paulo: Fundação Cargill, 2001. p. 7-28. 
